ISSN: 2277-3754

ISO 9001:2008 Certified

International Journal of Engineering and Innovative Technology (IJEIT)

Volume 10, Issue 2, August 2020

\title{
Impact of piezoelectric materials in electric vehicles
}

\author{
Koustubh Soudarthi, Mohammed Kaleemullah, Dr. B.V.S. Rao \\ Department of Mechanical Engineering \\ Chaitanya Bharathi Institute of Technology, Hyderabad, Telangana, India
}

\begin{abstract}
Alternative energy has become the need of the hour as environmental damage due to usage of fossil fuels sparks consumer awareness. Piezoelectricity is one of the most beneficial sources of electrical power if harnessed and applied properly. Today, its applications are limited. This paper discusses the potential application of piezoelectric materials in up and coming electric automobiles. This study is intended to increase the electric and overall efficiency of the system. Piezoelectricity has not been an accepted form of energy production because up until recent times, unconventional processes for producing power were frowned upon by people due to the misconception that alternate sources have low efficiency in comparison to the conventional sources. Today, there are multiple clean energy producing techniques which generate electrical power with decent efficiency. It is all about smartly applying and using these techniques at appropriate places. This paper discusses the possible scope, application and benefits of using piezoelectric materials in the electrical automobile sector. The motive is to obtain a pollution-free energy source and to utilize \& optimize the latent energy from applications where alternative mechanical stresses prevail. Piezoelectric materials are the future of energy production.
\end{abstract}

Keywords: Piezoelectricity, Green energy, Electric vehicles, alternative energy source, pollution free, smart materials.

\section{INTRODUCTION}

The inception of the concept of electric cars dates back to the 19th century. In fact, the first small-scale electric cart [1] was designed in the early 1830 s by Prof. Sibrandus Stratingh of the University of Groningen. After this, research and study began on this revolutionary concept of incorporating an electric motor in automobiles. Fig.1a and $1 \mathrm{~b}$ are visuals of the first forerunner of the electric car and Prof. Sibrandus Stratingh. Electric carriages working on batteries, electric rail-cars, amongst other types of vehicles were built by different researchers and scientists.

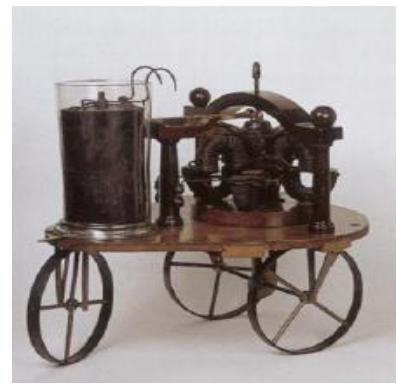

Fig. 1a. First forerunner of the electric car

\footnotetext{
Manuscript received: 30 July 2020

Manuscript received in revised form: 25 August 2020

Manuscript accepted: 10 September 2020

Manuscript Available online: 15 September 2020
}

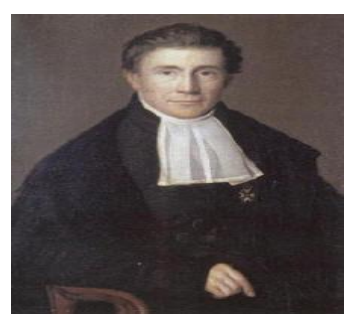

Fig. 1b. Sibrandus Stratingh

Although there were multiple drawbacks and problems associated with these models like low speed, inadequate electrical efficiency, high cost etc., the concept of electrical vehicles started turning eyes and gaining attention. This proves that an electrical vehicle is not a newfound technology. However, in the year 1908, when the company Ford started manufacturing cheap assembly line cars which made effective use of the internal combustion engine (invented in 1872), eventually the electric vehicle focus got diluted and took the back seat. Over the years, the automobile sector boomed. It witnessed a multifold growth in terms of innovations and research. IC engine based vehicles became the accepted normal in the society. In the latter half of the 20th century, began the incorporation of ergonomics in vehicular design [2] which focused on aspects like human-machine interaction. Fig. 2 shows a basic ergonomic design of the car seat.

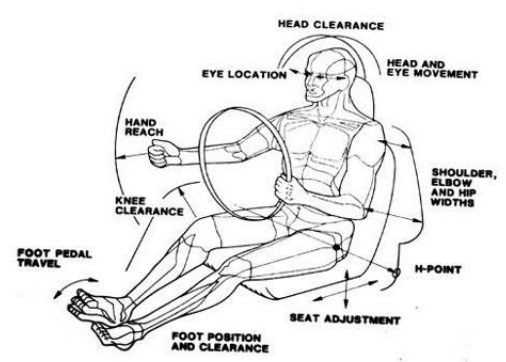

Fig. 2 A basic ergonomic design of the car seat

People then started noticing that the IC engines not only have a noisy operation but also release harmful gases into the atmosphere leading to extensive air pollution. In this context, the automobile sector, after trying to optimize the performance of IC engines, realized the need for an effective alternative and thus began its hunt for the next best alternative. This was the resurrection of the concept of Electric Vehicles (E.V.).

For the past several decades, countries have used fossil fuels, coal and other conventional sources for production of electricity. According to the National Oceanic and Atmospheric Administration (NOAA) 2019 Global climate 
ISSN: 2277-3754

ISO 9001:2008 Certified

International Journal of Engineering and Innovative Technology (IJEIT)

Volume 10, Issue 2, August 2020

summary [3], the combined average temperature of land and water has been increasing by nearly $0.32^{\circ}$ Fper decade since 1981 and this rate is accelerating with each passing year. This scary stat demands the shift from use of nonrenewable sources of energy to alternative green sources of energy while maintaining decent efficiency. This is precisely why this study on piezoelectricity has been conducted and its possible applications in the automobile sector are discussed. This paper emphasizes on incorporation of the said technology in E.V.s only as in conventional IC engine based vehicles, there is very little necessity of electricity.

\section{EXISTING PROBLEMS IN HYBRID AND FULLY ELECTRIC VEHICLES}

Electric vehicles cannot be used for long distance travels because of their limited range. Due to inadequate charging infrastructure, higher charging time and high charging costs, amongst other reasons, it is not feasible to use an electric vehicle for long distance travels.

Their speed is also low in comparison to the conventional IC engine based automobile. To overcome these drawbacks, Hybrid Electric Vehicles (H.E.Vs) gained popularity as they are powered by an IC engine in combination with one or more induction motors which run on batteries (electrical). Fig.3 and Fig.4 represent internal structures of E.V. AND H.E.V. structures respectively. [4]

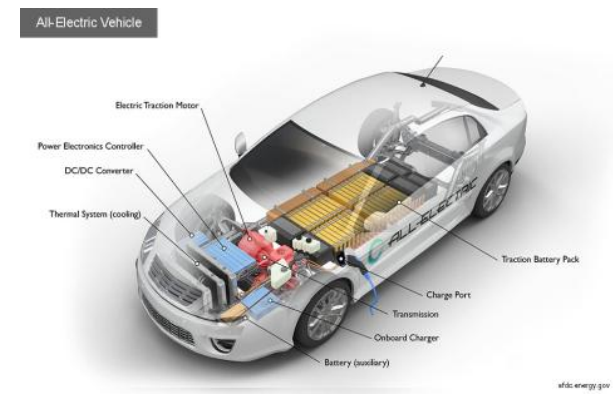

Fig. 3 Structure of Electric vehicle

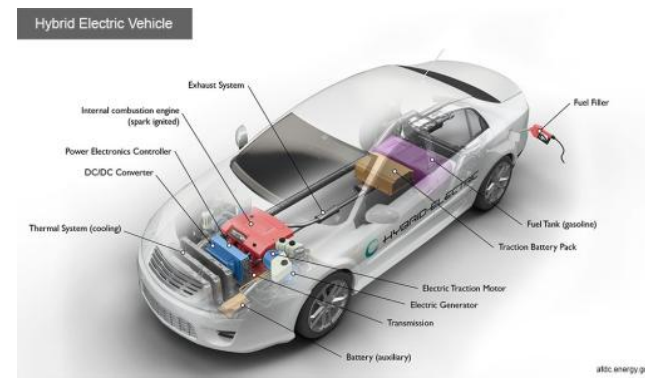

Fig. 4 Structure of Hybrid Electric vehicle

These vehicles require the engine to start so that the motor can run and thus challenging the purpose of having an electric car. Evidently, H.E.Vs are not pollution free modes of transport and do not aid to the environmental cause that is highly relevant in today's scenario. It is high time that we switch to automobiles which run on clean sources of energy which have minimal impact on the environment.

\section{PIEZOELECTRICITY: AN OVERVIEW}

Certain solid materials exhibit significant polarization under applied mechanical stress. This is predominantly observed in solid crystal lattices with no inversion symmetry. When pressure is applied on these materials, charges inside the substance start moving. Localized accumulation of similar charges is observed inside these lattice structures. Due to this localized accumulation of charges, there's an electric field and thus a potential difference set up within the structure which results in production of current. This phenomenon of producing electricity by certain materials being subjected to mechanical stresses is called piezoelectricity. Thus, it is evident that piezoelectricity is closely associated with the theory of electric dipole moments. A piezoelectric transducer is instrumental in harnessing piezoelectricity. It consists of a crystal sandwiched between 2 metal plates. When a stress is applied on any one or both the plates the plates vibrates and these vibration are in turn picked up by the crystal and are transformed into alternating voltage as shown in Fig 5. The following visual represents the working of a piezoelectric circuit: [5] there are several materials, both occurring naturally and artificially engineered, which exhibit piezoelectric effect.

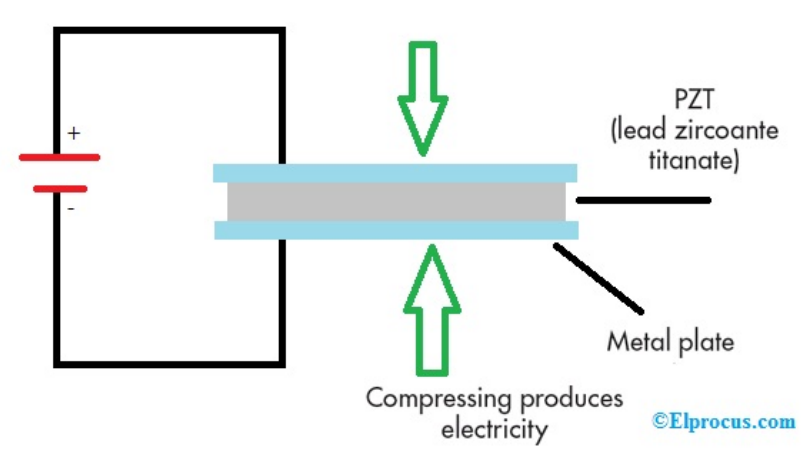

Fig. 5 Piezoelectric effect

Naturally occurring piezoelectric materials: Quartz, Cane Sugar, Rochelle salt, bone, Tourmaline amongst others

Artificially engineered piezoelectric materials: Barium titanate $\left(\mathrm{BaTiO}_{3}\right)$, Lead zirconate titanate (PZT), Potassium niobate $\left(\mathrm{KNbO}_{3}\right)$ amongst others.

Out of all the materials listed above, PZT is the most widely used piezoelectric material. These materials provide multiple benefits and facilitate green energy production as they exhibit the following characteristics:

1. Pollution free

2. Flexible and compact in size

3. Abundant availability

One might argue that there are more readily available alternative renewable sources of energy which can be put 


\section{ISSN: 2277-3754 \\ ISO 9001:2008 Certified \\ International Journal of Engineering and Innovative Technology (IJEIT) \\ Volume 10, Issue 2, August 2020}

to use but the following drawbacks are associated with the most popular conventional renewable resources:

Solar energy cannot be tapped as effectively in all seasons. The solar radiation differs from place to place and is also highly erratic which makes the power generation a function of weather and time.

Wind energy needs high velocity winds and enormous initial investment and land requirement, which makes it unaffordable to a lot of sections in society. Similar to solar energy, wind energy is also a function of weather, which makes it undesirable.

In addition to the highly unsafe operation and disposal of radioactive material, nuclear energy also is a heavy investment affair.

\section{METHODOLOGY}

\section{A. Incorporating piezoelectric crystals in Electrical} Vehicles

PZT (Lead zirconium titanate) is a very widely applied piezoelectric material. Substances called as piezoelectric benders are added to the PZT crystals in order to increase their flexibility. An array or series of multiple parallel arranged bendable PZT crystals are bonded to the inner surface of tyres as shown in the visual below [6]:

Fig. 6 shows the arrangement of piezoelectric array inside a rubber Tyre (the blue material being the array of crystals).

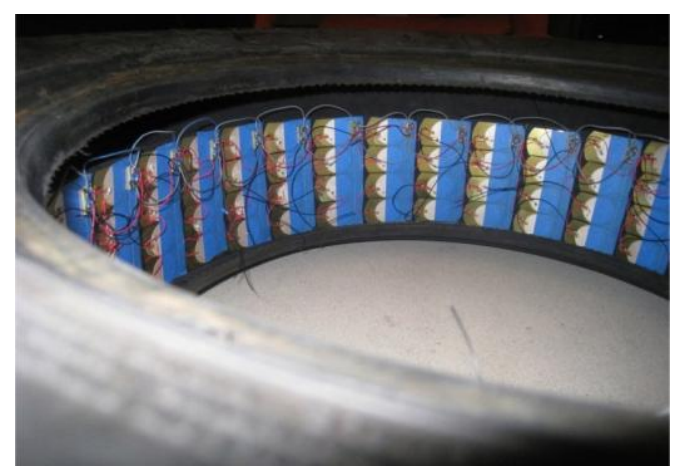

Fig. 6 PZT crystals arranged inside a tyre

When the vehicle is started and subsequently wheels of the vehicle start rotating and the automobile starts moving, due to the weight of the automobile, reaction from the ground and frictional loads act on the tyres and in turn these forces are transmitted to the piezoelectric system embedded inside the tyres. Due to the rotation of the wheels, the forces acting on each crystal at different points of time of a rotation fluctuate in magnitude. Due to these fluctuations, there are fluctuating mechanical stresses developed in the piezoelectric crystals. Due to this periodically varying stress induction in the crystals, there is distinct polarization of charges that is observed which in turn gives rise to a local electric field. Due to this field, naturally, a potential difference is set up across the system of crystals and a current is generated. Since there is an array of multiple crystals connected in series, small amounts of current from each crystal gets summed and a significant current is produced. The current produced is alternating in nature by the virtue of cyclic stresses induced. This current cannot be harnessed directly in an electrical vehicle since batteries only store DC power. Thus, the alternating current needs to be passed to a rectifier circuit to convert AC to DC. Finally, this power from the output of the rectifier is stored in the car battery.

\section{B. Case studies}

An experiment [7] was conducted by designing a suitable dynamometer to test the output power in such a way that the tyre is allowed to rotate at varying conditions of RPM. It was found that the average voltage is a function of both load and RPM. The impedance across the piezoelectric system installed was determined to be nearly one thousand ohms. For an average tyre size of 185/65R14; one with layers running radially $(\mathrm{R})$ across it, with a width of $185 \mathrm{~mm}$, a ratio of the height of the tire's cross-section to its width of 60 , and a wheel diameter of 14 inches, an electrical power of $2.3 \mathrm{~W}$ was found to be generated while the operating speed was roughly $100 \mathrm{~km} / \mathrm{h}$. The following graphical results were obtained when similar tests were repeated for varying values of RPM:

This paper discusses three case studies of electric cars manufactured by global market leaders:*

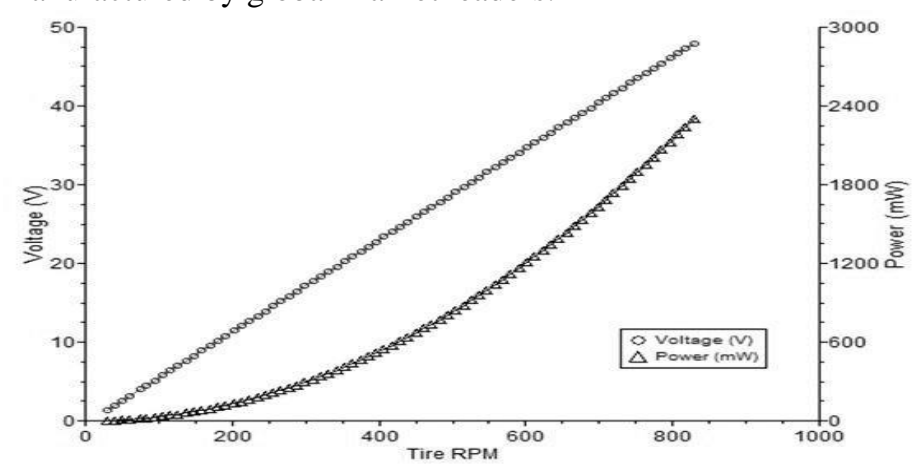

Fig. 7 Test results at different RPM

\section{Tesla model $X$ (2018) (shown in fig. 8)}

Specifications: [8]

- Horse power: 259

- Battery: $75 \mathrm{kWh}$

- Range: 238 miles

- Weight: $5185 \mathrm{lbs}$

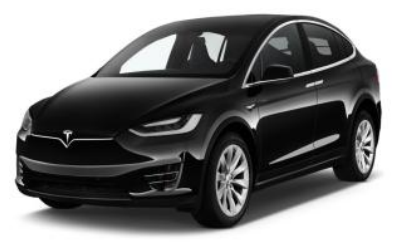

Fig.8 Tesla Model X (2018)

Annual fuel consumption cost $=(75 \times \$ 0.12 \times 14600) / 238=$ $\$ 552$ 


\section{ISSN: 2277-3754 \\ ISO 9001:2008 Certified \\ International Journal of Engineering and Innovative Technology (IJEIT) \\ Volume 10, Issue 2, August 2020}

\section{Specifications: [9]}

- Horsepower :143

- Battery:33.5kWh

- Range:115 miles

- Weight:3549 lbs

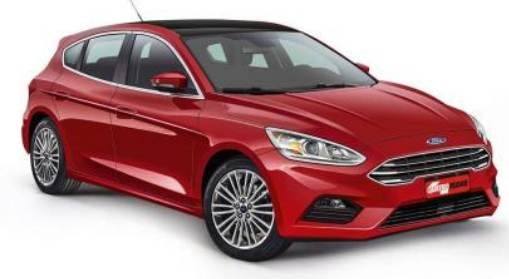

Fig.9 Ford Focus (2018)

Annual fuel consumption cost $=(33.5 \times \$ 0.12 \times 14600) / 115$ $=\$ 510.3$

3. Nissan Leaf (2020) (shown in fig.10)

Specifications: [10]

- Horsepower: 147

- Battery: $40 \mathrm{kWh}$

- Range: 149 miles

- Weight: $3538 \mathrm{lbs}$

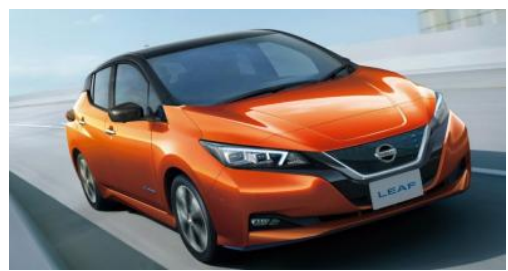

Fig.10 Nissan Leaf (2020)

Annual fuel consumption cost $=(40 \times \$ 0.12 \times 14600) / 149=$ $\$ 470$

Under similar test conditions as mentioned in [7], annual fuel consumption cost savings is a function of duration of use of the vehicle, distance travelled, weight of the vehicle and the passengers amongst others. In the aforementioned models, fuel consumption costs can be reduced by $2.1 \%$ to $\mathbf{2 . 8 \%}$ (with existing electrical technology).

*Note [11]: 1. A U.S citizen, on an average, travels 40 miles per day. With this estimate per year, a U.S. citizen travels about 14600 miles. 2. Average cost per unit of electricity is 12 cents.

\section{CONCLUSION}

This paper highlights the environmental and financial benefits that are associated with application of piezoelectric materials in the automobile industry. Similarly, the automobile industry is also welcoming automation by dwelling into futuristic and revolutionary concepts like driverless cars, electric vehicles, modular systems etc. Since all around the world, technology is rapidly progressing and adapting automation; it is the need of the hour to shift our focus on using alternative green sources of energy in every possible field. Piezoelectric materials behold immense potential to produce useful energy and incorporating these materials in electric vehicles can be the next industrial revolution of the vehicular sector. As discussed earlier in this paper, a net monetary saving of nearly $2.5 \%$ is achievable if electric vehicles in the United states incorporate the said technology. When, in the near future, E.Vs are introduced and become a new normal in India (a country with an exploding population and large number of private vehicle owners), use of piezoelectricity could lead to considerably high amount of saving, in addition to reduced environmental damage. Although this paper emphasizes the application of these materials in cars, it can easily be extended and applied in other modes of transport like 2wheelers, metro rails, buses amongst others.

Currently, the concept of piezoelectric effect is still in its initial stages because of certain drawbacks that are associated with it: 1 . when higher operating temperatures prevail, the energy generating capacity of the material is affected. ; 2 . The storage of generated energy is inefficient as it demands conversion from AC to DC. In the years to come, this field of piezoelectricity will turn heads and will develop exponentially, thereby eliminating the aforementioned limitations.

\section{REFERENCES}

[1] Kurian V Kurian, Sreejith Shaji, Ramkesh TM, Roshin Rajan, "PIEZOELECTRIC POWER GENERATION FROM TYRES",International Research Journal of Engineering and Technology (IRJET), Volume 05, Issue: 04 | Apr-2018.

[2] Zhixiang Li, Gongbo Zhou,, Zhencai Zhuand Wei Li, "A Study on the Power Generation Capacity of Piezoelectric Energy Harvesters with Different Fixation Modes and Adjustment Methods", MDPI Journal Energies,Vol,9(2),2016.

[3] https://www.electricvehiclesnews.com/History/historyearlyII .htm.

[4] http://www.dsource.in/course/basic-ergonomics-automotivedesign/module-2/introduction

[5] https://www.ncdc.noaa.gov/sotc/global/201913

[6] https://www.elprocus.com/what-is-the-piezoelectric-effectworking-and-its-applications/.

[7] https://spie.org/news/3702-piezoelectric-power-generationin-tires?.

[8] https://www.researchgate.net/publication/335353136_PIEZ O_ELECTRIC_GENERATOR_IN_CAR_TIRES.

[9] https://www.autoblog.com/buy/2018-Tesla-Model+X/specs/.

[10] https://www.guideautoweb.com/en/makes/ford/focus/2018/s pecifications/electric/.

[11] https://www.nissanusa.com/vehicles/electric-cars/leaf.html.

[12] https://www.bts.gov/statistical-products/surveys/nationalhousehold-travel-survey-daily-travel-quick-facts) 